\title{
Analysis of peripheral nerve and autonomic nervous system function and the stage of microangiopathy in patients with secondary Raynaud's phenomenon in the course of connective tissue diseases
}

\author{
Izabela Gosk-Bierska ${ }^{1, A}$, Maria Misterska-Skóra ${ }^{2, B}$, Marta Wasilewska, ${ }^{1, B}$, \\ Małgorzata Bilińska ${ }^{3, C}$, Jerzy Gosk ${ }^{4, D}$, Rajmund Adamiec ${ }^{1, E}$, Magdalena Koszewicz ${ }^{3, A, C}$ \\ ${ }^{1}$ Department of Angiology, Hypertension and Diabetology, Wroclaw Medical University, Poland \\ ${ }^{2}$ Department and Clinic of Rheumatology and Internal Medicine, Wroclaw Medical University, Poland \\ ${ }^{3}$ Department and Clinic of Neurology, Wroclaw Medical University, Poland \\ ${ }^{4}$ Clinical Department of Traumatology and Hand Surgery, Wroclaw Medical University, Poland \\ A - research concept and design; $\mathrm{B}$ - collection and/or assembly of data; $\mathrm{C}$ - data analysis and interpretation; \\ $D$ - writing the article; $E$ - critical revision of the article; $F$ - final approval of the article
}

Address for correspondence

Magdalena Koszewicz

E-mail:magdalena.koszewicz@umed.wroc.pl

Funding sources

None declared

Conflict of interest

None declared

Received on April 14, 2017

Reviewed on May 7, 2017

Accepted on July 1, 2017

\begin{abstract}
Background. The pathogenesis of secondary Raynaud's phenomenon (SRP) associated with connective tissue diseases (CTD) is not entirely understood. Nervous system dysfunction and microangiopathy are considered to be causes of this pathology.

Objectives. Peripheral and autonomic nervous system function, the stage of microangiopathy, and the relationships between these in patients with SRP were analyzed.

Material and methods. In the study, 20 patients with CTD-related SRP and 30 healthy controls were subject to capillaroscopy, standard conduction velocity tests and conduction velocity distribution (CVD) tests in ulnar and peroneal nerves, heart rate variability (HRV), and sympathetic skin response (SSR) tests.

Results. There were no significant differences in the standard motor and sensory conduction velocity tests, or in CVD tests in the ulnar and peroneal nerves in SRP patients compared with the controls. The patients with SRP had a significantly lower SSR amplitude and longer latency in hands and feet. The patients with CTD-related SRP had a significantly lower mean HRV with higher low frequency (LF) values in the spectral analysis and expiration/inspiration ratio (E/I) during deep breathing. There was no correlation between the stage of microangiopathy and neurophysiological test results.

Conclusions. Correct standard conduction velocity and CVD testing in patients with SPR suggest that vasomotor disturbances may occur in CTD regardless of peripheral neuropathy. The lack of relationship between SSR and microangiopathy could confirm that these 2 processes occur independently in patients with CTD-related SRP. Autonomic nervous system impairment together with normal peripheral nerve function suggest the central origin of CTD-related SRP.
\end{abstract}

Key words: microangiopathy, connective tissue diseases, secondary Raynaud's syndrome, peripheral nerves, autonomic nervous system

DOI

10.17219/acem/75618

Copyright

Copyright by Author(s)

This is an article distributed under the terms of the

Creative Commons Attribution Non-Commercial License

(http://creativecommons.org/licenses/by-nc-nd/4.0/) 


\section{Introduction}

Raynaud's phenomenon (RP) occurs as recurrent episodes of the discoloration of fingers and/or toes in the course of reversible vasospasm in response to cold or to emotional stress. ${ }^{1}$ Primary Raynaud's phenomenon (PRP) is diagnosed if the symptoms are idiopathic. Secondary Raynaud's phenomenon (SRP) is associated with different underlying diseases. SRP is a characteristic - although not specific - symptom of connective tissue diseases (CTD). SRP can overtake the development of the underlying disease by as much as several years, and, therefore, requires special observation. SRP occurs in $80 \%$ of patients with scleroderma, $10-35 \%$ of those with systemic lupus erythematosus, and $30 \%$ of dermatomyositis patients; it is the $1^{\text {st }}$ symptom of the disease in about $33 \%$ of systemic connective tissue diseases (CTD). ${ }^{2-6}$

Microangiopathy and nervous system dysfunctions are considered to be the causes of SRP in patients with CTD. Clinical symptoms in PRP are only a consequence of vasomotor disturbances without anatomical changes of the microcirculation; thus, in capillaroscopy the correct shape and number of loops arranged in parallel series are seen. SRP in the course of CTD, after periods of vasomotor disturbances of varying length, appears as organic microvascular changes, which lead to skin ulceration and/or necrosis of the fingers. Microangiopathy observed in nailfold capillaroscopy is a harbinger of digital necrosis and ulcers. ${ }^{3}$ The Maricq's et al. classification assesses the degree of microvascular damage, including morphological evaluation of the loops and their environment, and can be used in predicting the severity of vascular lesions. ${ }^{6}$

Peripheral nerve damage is observed in the course of CTD. The presence of specific antibodies, the deposition of immune complexes in peripheral nerves, and ischemic nerve injury secondary to vasculitis (vasa perineurium and vasa nervorum) are thought to be the main causes of neuropathy. ${ }^{7-10}$ In systemic lupus erythematosus (SLE), nervous system dysfunction is present in 19-38\% of cases, and the most common forms are multiple mononeuropathy, subacute or chronic axonal polyneuropathy, predominantly sensory, cranial neuropathy, and autonomic dysfunction. ${ }^{11}$ Mixed axonal polyneuropathy, multiple mononeuropathy, cranial neuropathy (nerves V and VIII with sudden bilateral hearing loss, and mild paroxysmal positional vertigo), compression syndromes, and myositis might occur in about $36 \%$ of patients with systemic scleroderma. Multiple mononeuropathies are particularly common in CREST syndrome - calcinosis, Raynaud's syndrome, esophageal dysmotility, sclerodactyly, teleangiectasia. ${ }^{7}$ Distal sensory neuropathy, carpal tunnel syndrome and other entrapment syndromes, and root syndrome as a result of the destruction of vertebral subluxation of the cervical spine are observed in rheumatoid arthritis. ${ }^{12}$ Thus, both microvascular disorder and peripheral nerve changes may influence the occurrence of SRP in patients with CTD.
The aim of our study was to analyze the peripheral nerve and autonomic nervous system function, the stage of microangiopathy and possible relationships between these in patients with Raynaud's phenomenon secondary to CTD.

\section{Material and methods}

The studies were approved by the Ethics Committee of Wroclaw Medical University, Poland. All patients gave their informed consent.

We investigated 20 patients ( 3 men, 17 women; mean age $49.1 \pm 11.8$ years old) with CTD-related SRP, and 30 healthy, age- and sex-matched controls. The following patients were excluded from the study: those with neurological disorders, primarily with neuropathy, compression syndrome (thoracic outlet syndrome, carpal tunnel syndrome), diabetes mellitus, malignancy, with exposure to neurotoxins and pharmacological treatment influencing the vascular and/ or autonomic nervous system, alcohol addiction, tobacco addiction, with limb ischemia (atherosclerosis, thromboangiitis obliterans, Takayasu's arteritis, hammer mild syndrome, vibration disease) and other dermatological abnormalities. To identify patients with these diseases, we analyzed medical histories; detailed neurological, orthopedic, and vascular examinations were performed as well. All patients underwent chest and cervical spine X-rays.

The following laboratory tests were performed on all patients using standard methods: complete blood cell count, erythrocyte sedimentation rate (ESR), rheumatoid factor, serum protein electrophoresis, immunoglobulin assessment, thyroid-stimulating hormone (TSH), anti-neutrophil cytoplasmic antibody tests (ANCA), c-cytoplasmic, p-perinuclear pattern, antinuclear antibody (ANA), Scl-70, SS-A (Ro), SS-B (La) antibody tests, and standard chemical screening.

Neurophysiological tests were performed on all subjects using Viking Select and Viking Quest Nicolet Biomedical devices (Nicolet Biomedical Inc., Madison, USA). Nerve conduction velocity tests (sensory and motor with F-wave estimation) were performed in median (in order to exclude carpal tunnel syndrome), ulnar and peroneal (sural) nerves using standard methods together with conduction velocity distribution (CVD) tests in ulnar and peroneal nerves. In the CVD test, we analyzed motor velocity ranges as the $10^{\text {th }}, 50^{\text {th }}$ and $90^{\text {th }}$ percentiles of the velocities..$^{13}$ Heart rate variability (HRV) was assessed at rest and during deep breathing. We analyzed R-R interval variability, shown as a percentage, and the expiration/inspiration ratio $(E / I)$, when the subject breathed at a rate of 6 breaths per minute. We used spectral analysis of R-R intervals with an estimation of low-frequency (LF, range between $0.04 \mathrm{~Hz}$ and $0.15 \mathrm{~Hz}$ ) and high-frequency (HF, range between $0.15 \mathrm{~Hz}$ and $0.4 \mathrm{~Hz}$ ) bands together with the LF/HF ratio. The sympathetic skin response (SSR) test was performed 
using the standard method (electrical stimulation of the right median nerve, recording from the left hand and foot). ${ }^{14-17}$

The subclavian, axillar, brachial, ulnar, and radial arteries were investigated via duplex ultrasound (GE Vivid 7, GE Healthcare, Little Chalfont, Great Britain) using a standard $9 \mathrm{MHZ}$ imaging probe (UST5539). The standard protocol in the laboratory included cross-sectional and longitudinal gray-scale and color Doppler imaging. ${ }^{18}$

A nailfold capillaroscopy examination was performed via widefield capillary microscopy using a Nikon SMZ 800 stereomicroscope (Nicon Instruments, Tokyo, Japan). All fingers except the thumbs were examined. Immersion oil was used to improve the transparency of the skin. Capillaries were viewed under 40 -fold magnification. Room temperature was between 20 and $22^{\circ} \mathrm{C}$.

On the basis of the Maricq's classification, we identified 2 groups depending on the morphological changes in the capillaries (NC group - patients with normal capillaries; DC group - patients with enlarged and/or deformed capillary loops) and 2 groups depending on the presence of avascular areas (AZ group - patients with a reduced number of capillaries or avascular zones; NAZ group - patients without avascular zones and a normal number of capillaries)..$^{6,19}$

The statistical analyses were performed using STATISTICA v. 5.0 PL (StatSoft, Tulsa, USA). Statistical significance was set at $\mathrm{p}<0.05$. Differences in baseline demographic and clinical variables were tested for significant differences between groups with ANOVA for continuous variables and Pearson's $X^{2}$ test for categorical variables. The Student's t-test and the Wilcoxon rank-sum test (when parameters were not distributed normally) were used to test for differences in the analyzed parameters between patients with Raynaud's phenomenon vs controls, and patients with microangiopathy vs patients without microangiopathy.

\section{Results}

In both groups, most of the patients were women (SRP - 85\%, controls - 83\%).

A total of $60 \%$ of patients manifested biphasic color changes (white and cyanotic phases without a red phase). The location of RP varied. RP was observed in 4 patients only in the hands.

All upper and lower extremities were the most common locations for RP. Only $15 \%$ of the patients presented additional locations of RP (earlobes, tip of the nose, penis).

The exact demographic and clinical characterization, including the etiology of SRP and the severity of microangiopathy, are presented in Table 1.

Standard neurophysiological test results (motor and sensory conduction in ulnar and peroneal nerves) were normal in all individuals. There were no significant statistical
Table 1. Demographic and clinical data for patients with SRP

\begin{tabular}{|c|c|}
\hline Variables & Data \\
\hline Age [years] & $49.1 \pm 11.8$ \\
\hline Female/male & $17 / 3$ \\
\hline Mean duration of SRP [years] & 9.8 (range 5-19) \\
\hline $\begin{array}{l}\text { Underlying disease: } \\
\text { scleroderma } \\
\text { systemic lupus erythematosus } \\
\text { rheumatoid arthritis } \\
\text { undifferentiated connective tissue disease }\end{array}$ & $\begin{array}{l}12(60 \%) \\
3(15 \%) \\
2(10 \%) \\
3(15 \%)\end{array}$ \\
\hline $\begin{array}{l}\text { Microangiopathy in capillaroscopy: } \\
\text { normal capillaries } \\
\text { dilatation of capillaries (loops giants) } \\
\text { normal numbers of capillaries } \\
\text { the presence of avascular zone }\end{array}$ & $\begin{array}{l}4(20 \%) \\
16(80 \%) \\
6(30 \%) \\
14(70 \%)\end{array}$ \\
\hline $\begin{array}{l}\text { Color changes during SRP } \\
\text { triphasic (pallor, cyanosis, redness) } \\
\text { biphasic (pallor, cyanosis) }\end{array}$ & $\begin{array}{c}8(40 \%) \\
12(60 \%)\end{array}$ \\
\hline $\begin{array}{l}\text { Localization of SRP } \\
\text { upper limbs only: } \\
\text { - fingers II, IV and V of right hand and fingers II-IV } \\
\text { of left hand, } \\
\text { - fingers II-V of both hands, } \\
\text { - fingers II-IV of both hands }\end{array}$ & $\begin{array}{c}4(20 \%) \\
1 \\
2 \\
1\end{array}$ \\
\hline $\begin{array}{l}\text { upper and lowers limbs: } \\
\text { - fingers II-V of both hands and all toes of both feet, } \\
\text { - fingers II, III, V of right hand, fingers III, IV of left } \\
\text { hand and all toes of both feet, } \\
\text { - fingers II, III of right hand, fingers III, IV of left hand } \\
\text { and all toes of both feet, } \\
\text { - all fingers of both hands and all toes of both feet }\end{array}$ & $\begin{array}{c}13(65 \%) \\
8 \\
1 \\
1 \\
3\end{array}$ \\
\hline $\begin{array}{l}\text { limbs and other localization: } \\
\text { - whole hands and feet, earlobes, tip of the nose, } \\
\text { penis, } \\
\text { - fingers II-V of both hands and all toes of both } \\
\text { feet, earlobes, tip of the nose, } \\
\text { - all fingers of both hands and all toes of both feet, } \\
\text { tip of the nose }\end{array}$ & $\begin{array}{c}3(15 \%) \\
1 \\
1 \\
1\end{array}$ \\
\hline $\begin{array}{l}\text { Sclerodactylia } \\
\text { Tingling, numbness, stinging, burning of fingers: } \\
\text { - at the time of the RP, } \\
\text { - permanent }\end{array}$ & $\begin{array}{l}6(30 \%) \\
18(90 \%) \\
8(40 \%)\end{array}$ \\
\hline $\begin{array}{l}\text { Stiffness of the fingers or toes } \\
\text { Subjective reduction of sensation in fingers or toes } \\
\text { Pain in small joints of hands }\end{array}$ & $\begin{array}{c}6(30 \%) \\
6(30 \%) \\
10(50 \%)\end{array}$ \\
\hline
\end{tabular}

SRP - secondary Raynaud's phenomenon.

differences in the conduction velocity distribution in the ulnar and peroneal nerves in the group with SRP compared with the control group (Table 2).

In patients with SRP, a significantly lower SSR amplitude and a longer latency were shown in relation to the control group. Changes were more pronounced in the lower limbs (Table 3). The study showed a complete lack of SSR in upper and lower limbs in 2 patients (1 with scleroderma and 1 with SLE), and lack of SSR in the lower limbs in another 2 patients ( 1 individual with undifferentiated connective tissue disease and 1 individual with scleroderma). Lack of SSR was found in patients with varying severities 
Table 2. Comparison of conduction velocity distribution in study groups and subgroups

\begin{tabular}{|c|c|c|c|}
\hline $\begin{array}{l}\text { SRP vs control } \\
\text { CVD [m/sec] }\end{array}$ & $\begin{array}{c}\text { SRP } \\
(n=20)\end{array}$ & $\begin{array}{l}\text { Control } \\
(n=30)\end{array}$ & $p$-value \\
\hline \multicolumn{4}{|c|}{ Ulnar nerve } \\
\hline CVD 10\% & $45.5 \pm 7.1$ & $47.5 \pm 5.5$ & ns \\
\hline CVD 50\% & $51.2 \pm 7.1$ & $54.3 \pm 5.4$ & ns \\
\hline CVD 90\% & $57.1 \pm 6.6$ & $59.1 \pm 6.1$ & ns \\
\hline \multicolumn{4}{|c|}{ Peroneal nerve } \\
\hline CVD 10\% & $39.9 \pm 2.1$ & $40.7 \pm 2.5$ & ns \\
\hline CVD 50\% & $43.9 \pm 2.5$ & $45.1 \pm 2.8$ & ns \\
\hline CVD 90\% & $46.9 \pm 2.4$ & $48.4 \pm 2.6$ & ns \\
\hline $\begin{array}{l}\text { NC vs DC } \\
\text { CVD }[\mathrm{m} / \mathrm{s}]\end{array}$ & $\begin{array}{c}N C \\
(n=4)\end{array}$ & $\begin{array}{c}\text { DC } \\
(n=16)\end{array}$ & $p$-value \\
\hline \multicolumn{4}{|c|}{ Ulnar nerve } \\
\hline CVD 10\% & $46.1 \pm 6.7$ & $45.2 \pm 6.4$ & ns \\
\hline CVD 50\% & $50.8 \pm 9.5$ & $51.3 \pm 5.7$ & ns \\
\hline CVD 90\% & $56.4 \pm 6.8$ & $57.4 \pm 6.9$ & ns \\
\hline \multicolumn{4}{|c|}{ Peroneal nerve } \\
\hline CVD 10\% & $38.9 \pm 2.1$ & $39.4 \pm 2.3$ & ns \\
\hline CVD 50\% & $43.1 \pm 2.1$ & $43.4 \pm 2.4$ & ns \\
\hline CVD 90\% & $45.9 \pm 1.7$ & $46.4 \pm 2.4$ & ns \\
\hline $\begin{array}{l}\text { NAZ vs AZ } \\
\text { CVD [m/s] }\end{array}$ & $\begin{array}{c}\text { NAZ } \\
(n=8)\end{array}$ & $\begin{array}{c}A Z \\
(n=12)\end{array}$ & $p$-value \\
\hline \multicolumn{4}{|c|}{ Ulnar nerve } \\
\hline CVD 10\% & $46.5 \pm 6.4$ & $44.1 \pm 6.5$ & ns \\
\hline CVD 50\% & $51.7 \pm 8.1$ & $50.5 \pm 5.7$ & ns \\
\hline CVD 90\% & $57.6 \pm 7.4$ & $56.2 \pm 5.7$ & ns \\
\hline \multicolumn{4}{|c|}{ Peroneal nerve } \\
\hline CVD 10\% & $39.3 \pm 2.1$ & $39.3 \pm 2.6$ & ns \\
\hline CVD 50\% & $43.6 \pm 2.1$ & $42.7 \pm 2.4$ & ns \\
\hline CVD 90\% & $46.5 \pm 2.3$ & $45.7 \pm 2.1$ & ns \\
\hline
\end{tabular}

CVD - conduction velocity distribution; SRP - secondary Raynaud's phenomenon; NC - normal capillaries; DC - dilatation of capillaries (giant loops); NAZ - no avascular zone (normal numbers of capillaries); AZ - the presence of an avascular zone; ns - non-significant.

of microvascular complications (2 patients without microangiopathy, 2 patients with microangiopathy). SSR showed no relationship with the severity of the microangiopathy (Fig. 1). There were no statistical differences in terms of SSR between patients with normal numbers of capillaries compared with the subgroup with avascular zones in capillaroscopy. There were also no differences in SSR results between patients with normal capillaries and individuals with dilatation of capillaries.

Statistical analysis showed a significantly lower mean HRV, and higher LF values, LF/HF ratio, and E/I ratio in patients with SRP than in the control group (Table 4).

There was no correlation between the stage of microangiopathy and neurophysiological tests (standard conduction velocity, CVD, SSR).
Table 3. Comparison of sympathetic skin response (SSR) between study groups and subgroups

\begin{tabular}{|c|c|c|c|}
\hline SRP vs control & $\begin{array}{c}\text { SRP } \\
(n=20)\end{array}$ & $\begin{array}{l}\text { Controls } \\
(n=30)\end{array}$ & $\mathrm{p}$-value \\
\hline Palm latency [ms] & $1,544 \pm 163$ & $1,522 \pm 116$ & 0.04393 \\
\hline Palm amplitude [mV] & $2,155 \pm 1,809$ & $3,122 \pm 1,815$ & 0.00298 \\
\hline Foot latency [msec] & $2,416 \pm 562$ & $2,174 \pm 237$ & 0.03798 \\
\hline Foot amplitude [mV] & $944 \pm 847$ & $2,230 \pm 1,221$ & 0.00041 \\
\hline NC vs DC & $\begin{array}{c}N C \\
(n=4)\end{array}$ & $\begin{array}{c}D C \\
(n=16)\end{array}$ & $\mathrm{p}$-value \\
\hline Palm latency [ms] & $1,496 \pm 227$ & $1,492 \pm 208$ & ns \\
\hline Palm amplitude [mV] & $2,010 \pm 2,023$ & $2,467 \pm 1,504$ & ns \\
\hline Foot latency [ms] & $2,310 \pm 256$ & $2,355 \pm 526$ & ns \\
\hline Foot amplitude [mV] & $856 \pm 1,057$ & $1,181 \pm 820$ & ns \\
\hline NAZ vs $A Z$ & $\begin{array}{c}\text { NAZ } \\
(n=8)\end{array}$ & $\begin{array}{c}A Z \\
(n=12)\end{array}$ & $\mathrm{p}$-value \\
\hline Palm latency [ms] & $1,482 \pm 254$ & $1,500 \pm 183$ & ns \\
\hline Palm amplitude [mV] & $2,120 \pm 2,197$ & $2,754 \pm 1,304$ & ns \\
\hline Foot latency [ms] & $2,290 \pm 281$ & $2,376 \pm 560$ & ns \\
\hline Foot amplitude [mV] & $1,161 \pm 1,030$ & $990 \pm 814$ & ns \\
\hline
\end{tabular}

SSR - sympathetic skin response; SRP - secondary Raynaud's phenomenon; NC - normal capillaries; DC - dilatation of capillaries (giant loops); NAZ - no avascular zone (normal numbers of capillaries); $A Z$ - the presence of avascular zone; ns - non-significant.

Table 4. Comparison of heart rate variability in study groups

\begin{tabular}{|l|c|c|c|} 
Heart rate data & $\begin{array}{c}\text { SRP } \\
(n=20)\end{array}$ & $\begin{array}{c}\text { Control } \\
(n=30)\end{array}$ & $p$-value \\
\hline HRV (\%) & $13.5 \pm 4.4$ & $24.1 \pm 6.5$ & 0.000000 \\
\hline LF (bpm) & $53.1 \pm 22.3$ & $40.92 \pm 9.2$ & 0.018111 \\
\hline HF (bpm) & $14.1 \pm 6.4$ & $12.4 \pm 6.9$ & 0.431469 \\
\hline LF/HF & $3.9 \pm 0.5$ & $3.4 \pm 0.6$ & 0.027669 \\
\hline E/I & $1.1 \pm 0.09$ & $1.3 \pm 0.15$ & 0.001424 \\
\hline
\end{tabular}

HRV - heart rate variability; LF - low frequency; HF - high frequency; E/I - expiration/inspiration ratio.

\section{Discussion}

This study is a continuation of our previous research on the pathogenesis of primary Raynaud's phenomenon. ${ }^{15,20}$ In the present study, we analyze the role of the peripheral nervous system in patients with SRP in the course of CTD.

Typical peripheral nervous system lesions in the course of different connective tissue diseases mainly include axonal, ischemic peripheral nerve damage (distal sensory polyneuropathy, mononeuropathy/multiple mononeuropathy, cranial neuropathy), and myopathy. Therefore, Raynaud's phenomenon in CTD is thought to be secondary to the dysfunction of the peripheral nervous system. It would be interesting to answer the question as to whether patients with SRP without clinical evidence of peripheral neuropathy may have autonomic dysfunction. 


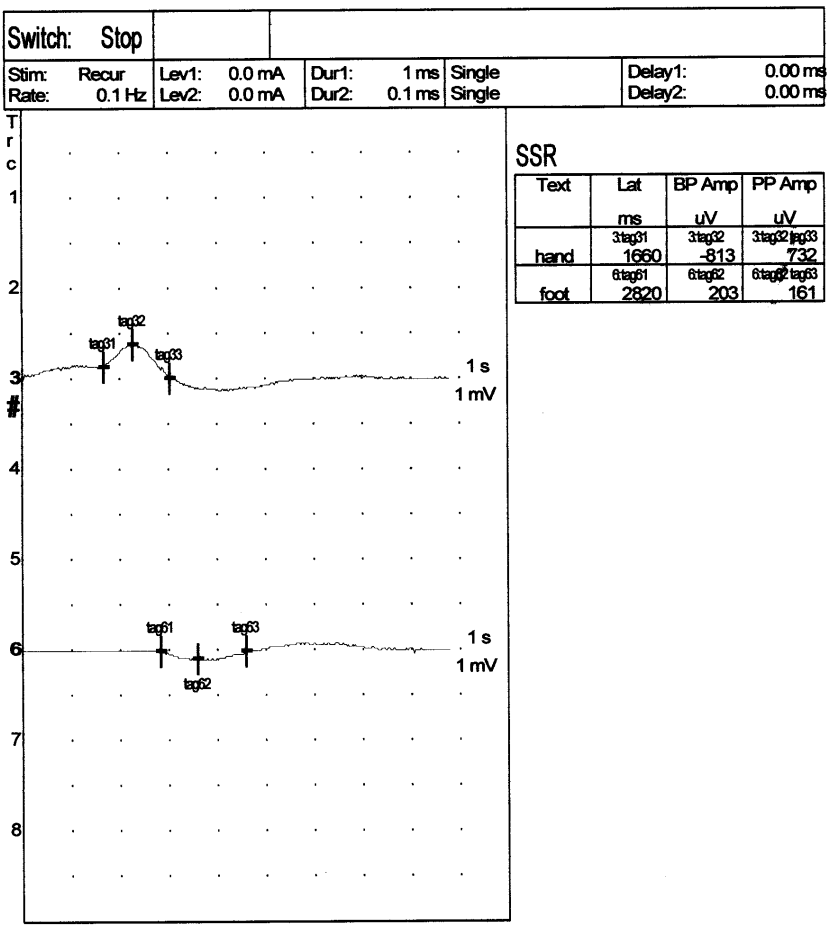

Fig. 1. K.M, woman, 48 years old, with rheumatoid arthritis,

in capillaroscopy: capillaries without loops giants, no avascular zone. Abnormal sympathetic skin response (SSR): Iow amplitude, long latencies from hand and foot

Previous research into nervous system disorders in the pathogenesis of RP has been performed on patients with PRP, and these studies have shown that the pathogenesis of PRP is multifactorial and includes the sympathetic peripheral nervous system, central neural abnormalities and local defects. ${ }^{15,20-22}$ Mondelli et al. showed dysregulation of cholinergic sympathetic fibers innervating the fingers in PRP. Abnormal SSR habituation has suggested that the central mechanism should also be considered. ${ }^{22}$

According to Charkoudian, the sympathetic nervous system is involved in the pathogenesis of both primary and secondary Raynaud's phenomenon, both in peripheral (local) and central system involvement mechanisms. ${ }^{23}$

In the opinion of Kaheleh et al., Raynaud's phenomenon is the result of dysregulated neuroendothelial control of vascular tone and circulating mediators. ${ }^{24}$ These mechanisms are suggested as playing a major role in secondary Raynaud's phenomenon due to scleroderma.

In our study, detailed neurological and orthopedic examinations and standard neurophysiological tests, together with CVD and an analysis of different fibers in motor nerves (CVD test) were performed in order to exclude peripheral neuropathy. There were no significant statistical differences in these tests in the ulnar and peroneal nerves in the SRP group compared with the control group. Therefore, we assumed that vasomotor disturbances may occur in CTD regardless of peripheral neuropathy.

Central neural abnormalities are considered a cause of RP. Our study indicated sympathetic hyperactivity and the attenuation of the parasympathetic influence of heart rate. Similar abnormalities have previously been observed in patients with PRP. ${ }^{15}$ According to Edwards et al.'s studies, patients with PRP present an abnormality of the central neuronal modulation of the brainstem with impaired habituations of vasodilator and vasoconstriction components of the warning system responsible for emotional stress. ${ }^{25}$ The results of our study also suggest that SRP in the course of CTD, and without peripheral neuropathy, could be a consequence of central impairment of neuronal habituation.

In our study, similar to the previous one in PRP patients, we revealed the impairment of sympathetic sweat fibers, which could suggest that small autonomic fibers are damaged. The changes were more evident in lower limbs, which could be explained by their longer nerves, which are more susceptible to any disturbance to regenerative processes. In standard neurographic tests and CVD tests, we did not reveal any changes, so only very small fiber neuropathy (type $\mathrm{C}$ and unmyelinated fibers) could be found in SRP patients. The lack of correlation between SSR changes and microangiopathy indicates that SSR dysfunction in patients with SRP occurs regardless of structural changes in the capillaries. Further observations as to whether the SSR can be an independent predictor of skin necrosis must be conducted.

\section{Conclusions}

Correct standard conduction velocity and CVD tests in patients with SPR allow for the supposition that vasomotor disturbances may occur in CTD regardless of peripheral neuropathy.

The lack of a relationship between SSR and microangiopathy can confirm that these 2 processes occur independently in patients with CTD-related SRP.

Normal peripheral nerve function, together with revealed autonomic nervous system impairment, suggests the central origin of SRP in the course of CTD.

\section{References}

1. Raynaud M. On local asphyxia and symmetrical gangrene of the extremities 1862. New researches on the nature and treatment of local asphyxia of the extremities. In: Barlow T, trans. Selected monographs. London, UK: New Sydenham Society; 1874.

2. Harper FE, Maricq HR, Turner RE, et al. A prospective study of Raynaud's phenomenon and early CTD. A five-year report. Am J Med. 1982;72:883-888.

3. Herrick AL. Pathogenesis of Raynaud's phenomenon. Rheumatology. 2005;44:587-596.

4. Pavlov-Dolijanovic S, Damjanov NS, Stojanovic RM, et al. Scleroderma pattern of nailfold capillary changes as predictive value for the development of a connective tissue disease: A follow-up study of 3,029 patients with primary Raynaud's phenomenon. Rheumatol Int. 2012;32(10):3039-3045.

5. Wu PC, Huang MN, Kuo YM, Hsieh SC, Yu CL. Clinical applicability of quantitative nailfold capillaroscopy in differential diagnosis of connective tissue diseases with Raynaud's phenomenon. J Formos Med Assoc. 2013;112(8):482-488. 
6. Maricq HR, Le Roy EC, D'Angelo WA, et al. Diagnostic potential of in vivo capillary microscopy in scleroderma and related disorders. Arthritis Rheum. 1980;23:183-189.

7. Andreadou E, Zouvelou V, Karandreas N, et al. Anti-myelin-associated glycoprotein polyneuropathy coexistent with CREST syndrome. J Postgrad Med. 2012;58:57-59.

8. Gunatilake SS, Wimalaratna H. Guillain-Barré syndrome presenting with Raynaud's syndrome. A case report. BMC Neurol. 2014;14:174.

9. Jasmin R, Sockalingam S, Ramanaidu LP, Goh KJ. Clinical and electrophysiological characteristics of symmetric polyneuropathy in a cohort of systemic lupus erythematosus patients. Lupus. 2015; 24(3):248-255.

10. Omdal R, Bekkelund SI, Meligren SI, et al. C-fibre function in systemic lupus erythematosus. Lupus. 1996;5:613-617.

11. Hanly JG, Urowitz MB, Sanchez-Guerrero J, et al. Systemic Lupus International Collaborating Clinics. Neuropsychiatric events at the time of diagnosis of systemic lupus erythematosus: An international inception cohort study. Arthritis Rheum. 2007;56:265-273.

12. Sim MK, Kim DY, Yoon J, et al. Assessment of peripheral neuropathy in patients with rheumatoid arthritis who complain of neurologic symptoms. Ann Rehabil Med. 2014;38:249-255.

13. Oh SJ. Clinical Electromyography: Nerve Conduction Studies. Lippincott, PA: Williams and Wilkins; 2003.

14. Kleiger RE, Stein PK, Bigger JT. Heart rate variability: Measurement and clinical utility. Ann Noninvasive Electrocardiol. 2005;10:88-101.

15. Koszewicz M, Gosk-Bierska I, Bilińska M, et al. Autonomic dysfunction in primary Raynaud's phenomenon. Int Angiol. 2009;28:127-131.

16. Elie B, Guiheneuc P. Sympathetic skin response: Normal results in different experimental conditions. Electroencephalogr Clin Neurophysiol. 1990;6:258-267.
17. Uncini A, Pullman SL, Lovelace RE, et al. The sympathetic skin response: Normal values, elucidation of afferent components and application limits. J Neurol Sci. 1988;87:299-306.

18. Gerhard-Herman M, Gardin JM, Jaff M, et al. Guidelines for noninvasive vascular laboratory testing: A Report from the American Society of Echocardiography and the Society of Vascular Medicine and Biology. J Am Soc Echocardiogr. 2006;19:955-972.

19. Maricq HR. Widefield capillary microscopy. Technique and rating scale for abnormalities seen in scleroderma and related disorders. Arthritis Rheumatol. 1981;24:1159-1166.

20. Koszewicz M, Gosk-Bierska I, Gosk J, et al. Peripheral nerve changes assessed by conduction velocity distribution in patients with primary Raynaud's phenomenon and dysautonomia. Int Angiol. 2011;30: 375-379.

21. Manek NJ, Holmgren AR, Sandroni P, et al. Primary Raynaud's phenomenon and small-fibre neuropathy: Is there a connection? A pilot neurophysiologic study. Rheumatol Int. 2011;31:577-585.

22. Mondelli M, Romano C, De Stefano R, et al. Nerve conduction velocity study of the upper limb in Raynaud's phenomenon. Rheumatol Int. 2000;19:165-169.

23. Charkoudian N. Skin blood flow in adult human thermoregulation: How it works, when it does not, and why. Mayo Clin Proc. 2003;78: 603-612.

24. Kaheleh B, Matucci-Cerinic M. Raynaud's phenomenon and scleroderma. Dysregulated neuroendothelial control of vascular tone. Arthritis Rheumatol. 1995;38:1-4.

25. Edwards CM, Marshall JM, Pugh M. Lack of habituation of the pattern of cardiovascular response evoked by sound in subject with primary Raynaud's disease. Clin Sci. 1998;95:249-260. 